\title{
Use of a 2-layer thermoelectric generator structure for photovoltaics cells cooling and energy recovery
}

\author{
Stawomir Wnuk ${ }^{1, *}$, George Loumakis ${ }^{1}$, and Roberto Ramirez-Iniguez ${ }^{1}$ \\ ${ }^{1}$ School of Engineering \& Built Environment, Glasgow Caledonian University, 70 Cowcaddens Road, \\ Glasgow G4 0BA, Scotland, UK
}

\begin{abstract}
A 2-layer thermoelectric generator was tested as a solution to increase the output of a PV cell. A number of practical experiments were carried out on both single and two combined thermoelectric generator (TEG) configurations connected in series with photovoltaic (PV) cells and connected to a load independently from each other. Testing was performed using a class AAA solar simulator system Sol3A and under real outdoor weather conditions. The results show a reduction of the maximum cell temperature by $10.3{ }^{\circ} \mathrm{C}$ on average and at the same time an increase in the tested photovoltaics-thermo-generators (PV-TEGs) voltage output of the proposed hybrid systems by $28.56-30.54 \%$ compared to the plain PV cell. It was experimentally confirmed that the TEGs-PV structure performs better than the bare PV cell during decline of insolation utilising, in addition to the limited at this time solar energy, the heat accumulated by the multilayer structure components. Experiments showed that for the selected period of time (1600s) the energy output increased by $27.6 \%$ compared to a plain PV cell. For a constant level of artifical light $\left(1000 \mathrm{~W} / \mathrm{m}^{2}\right)$ the PV-TEG's hybrid system showed an increase of energy yield of $3.1 \%$ compared to a plain PV system.
\end{abstract}

\section{INTRODUCTION}

Polycrystalline PV cells have been used for solar energy conversion for many years offering a form of sustainable, renewable, and environmentally friendly energy. Accordingly to REN 212020 [1], the world as of the end of 2019 had a capacity of installed PV systems of almost $627 \mathrm{GW}$ compared to less than $40 \mathrm{GW}$ ten years ago. Polycrystalline PV cells have low manufacturing costs compared to their monocrystalline counterparts, but their efficiency leaves room for significant improvement [2]. The amount of electrical energy gained from the solar panels installations is decisively lowered by temperature increase in the PV cells [3]. In pursue to improve their performance; various methods involving the cooling of the PV cells have been investigated by other researchers [4]. The cooling methods can be divided into active and passive methods, depending on whether an external energy source for cooling is applied [5].

Arifin et. al. [6] performed theoretical and experimental research of air cooling for PV panels using aluminum heat sinks. Kim et. al [7] investigated a heat sink in the form of a metal mesh. Rakin et. al. [8] tested the use of a combined water and heat sink passive cooling system. Yusoff et. al. [9] proposed an active PV cooling system utilizing DC fans.

Apart from the passive [6, 7, 8] and active cooling methods [9], TEGs which utilized both Thomson and Peltier and Seebeck [10] effects were investigated [11].

* Corresponding author Slawomir.Wnuk@gcu.ac.uk 
By definition, TEGs are semiconductor devices that employ the Seebeck effect in thermopiles to convert the temperature gradient induced by waste heat into electrical power. In practice a TEG structure consist of a number of thermocouples. The thermo-elements built of $\mathrm{p}$ and $\mathrm{n}$ type semiconductors are sandwiched between two ceramic plates, which are to be held at two different temperatures to create electrical energy generation. A temperature gradient induced between top and bottom ceramic plates creates voltage on the TEG poles due to the Seebeck effect [12]. Research on using TEGs for PV cell efficiency improvement has been conducted on both theoretical [13] and practical [14] hybrid systems applications.

Apart from the abovementioned methods, an innovative and promising solution to the drop in output of PV cells due to temperature increase could be to use a multilayer TEG semiconductor device in tandem with a PV cell. In this paper a system configuration using a heat sink and a TEG structure at the same time is examined.

\section{METHODOLOGY}

The experiments were conducted using several small models of the proposed PV-TEGs hybrid system which elements are described as follows:

- Polycrystalline silicone PV cells with active dimensions 40x40 mm and declared by manufacturer maximum voltage/current outputs $1.5 \mathrm{~V} / 150 \mathrm{~mA}$ for standard test conditions (STC) with solar energy conversion efficiency of $18 \%$ and temperature coefficient of $\mathrm{V}_{\text {oc }}-0.37 \% / \mathrm{C}^{\circ}$

- Thermoelectric generator: A type SP1848-27145 device made of bismuth telluride $\left(\mathrm{Bi}_{2} \mathrm{Te}_{3}\right)$ with the optimum value $(\mathrm{Z}): 2.5 \sim 3 \times 10-3 \mathrm{~W} /{ }^{\circ} \mathrm{C}$, the temperature electromotive force (a): $>190 \mathrm{x} \mu \mathrm{V} /{ }^{\circ} \mathrm{C}$, the thermal conductivity (K): $15 \sim 16 \times 10^{-3}-\mathrm{W} /{ }^{\circ} \mathrm{C} \mathrm{cm}, 20$ degree temperature difference: open-circuit voltage $0.97 \mathrm{~V}$, generated current $225 \mathrm{~mA}$. The TEG was selected with the matching to the PV cells' dimensions of 40x40 mm.

- Thermoelectric cooler (TEC) used as a heat source in its reversed position (hot side) of the popular type TEC1-12706 with dimensions $40 \times 40 \mathrm{~mm}$, supplied by a 12 VDC power source.

- Passive cooler: the unit was made of aluminum with overall size 40x40×20 mm.

- A class AAA solar simulator Sol3A utilized as the source of the solar light in the indoor experiments.

The outdoor experiments were conducted in April 2020 in Glasgow North in the outdoor setting. The measurement devices used were:

- Keithley 2440 digital source meter.

- Velleman PCS10/K8047 4-channels data logger.

- $\quad$ True RMS Digital Multi Tester with USB Mercury MTTR0.

The experiments were carried out in three stages with the purpose of each being:

- Obtaining real power/voltage characteristics of the tested photovoltaics cells for a selected temperature range.

- Determining the temperature characteristics of the multilayer TEGs structure with TEGs connected both in series and in parallel.

- The practical testing of the proposed hybrid PV-TEGs system under both the laboratory artificial light source and the outdoor natural sun irradiation environment. 


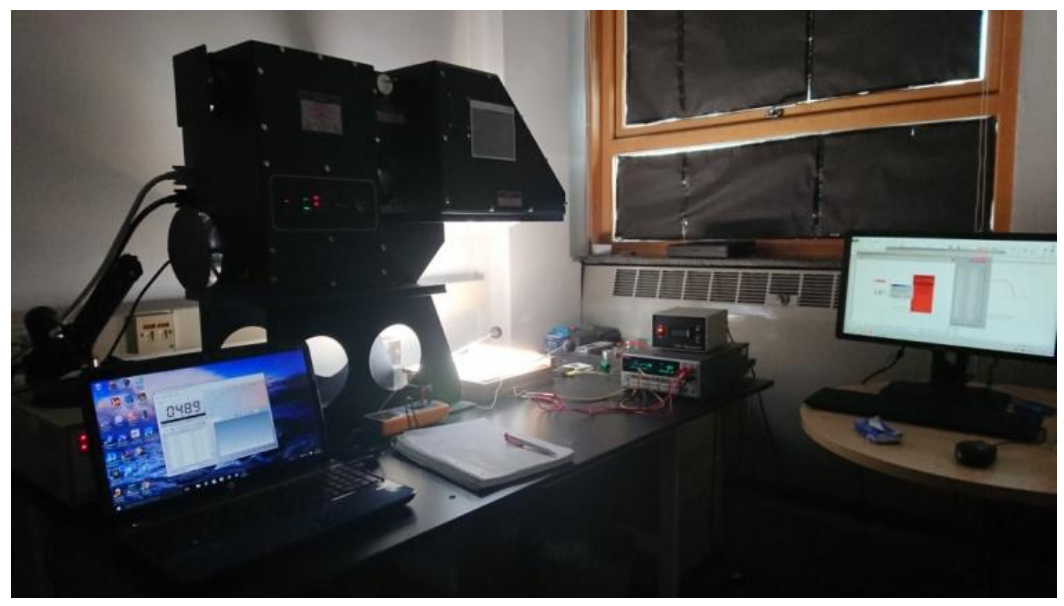

Fig.1 Example of laboratory test equipment arrangement

\section{PHOTOVOLTAICS CELLS CHARACTERISTICS}

The aim of the first stage of the experiments was to determine the power characteristics for the variation of temperature of the PV cells exposed to irradiation of $1000 \mathrm{~W} / \mathrm{m}^{2}$ at a constant ambient temperature of $25^{\circ} \mathrm{C}$ for some amount of time. The obtained temperature and power characteristics provide the base for comparison for further investigation. The initial step of the experiments was finding the maximum temperature to which the tested uncooled solar cells would heat up when exposed to solar radiation. For the tests the artificial solar light simulator Sol3A series was set to provide a constant 1000 $\mathrm{W} / \mathrm{m}^{2}$. After 74 minutes of starting the test the PV cells temperature increased from $20^{\circ} \mathrm{C}$ up to $65.7^{\circ} \mathrm{C}$ and stabilized at this level. The obtained temperature range was used in further investigation and calculations.

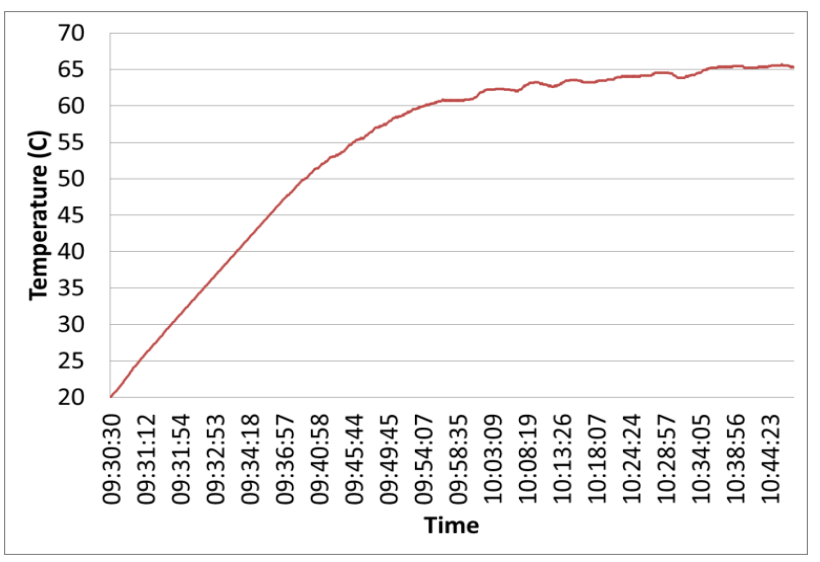

Fig.2 PV cells temperature chart for STC conditions, ambient temperature (Ta) $25^{\circ} \mathrm{C}$

Having established the practical polycrystalline PV cells temperature range the power/voltage (P-V) characteristics were obtained in a series of the laboratory tests under the same conditions for various cell temperatures. The same artificial solar power irradiation level of $1000 \mathrm{~W} / \mathrm{m}^{2}$ was set up as previously. A Keithley 2440 digital source meter was used for measurement of the P-V. The aim of the experiments was obtaining 
comparative data such as $\mathrm{P}-\mathrm{V}$ characteristics, amounts of energy gained, maximum power points (MPP) for further experiments on the hybrid PV-TEGs systems. P-V characteristics of the experiments for a number of temperature points selected at equal intervals within the temperature range established in the previous experiment are presented on the Fig. 3 below.

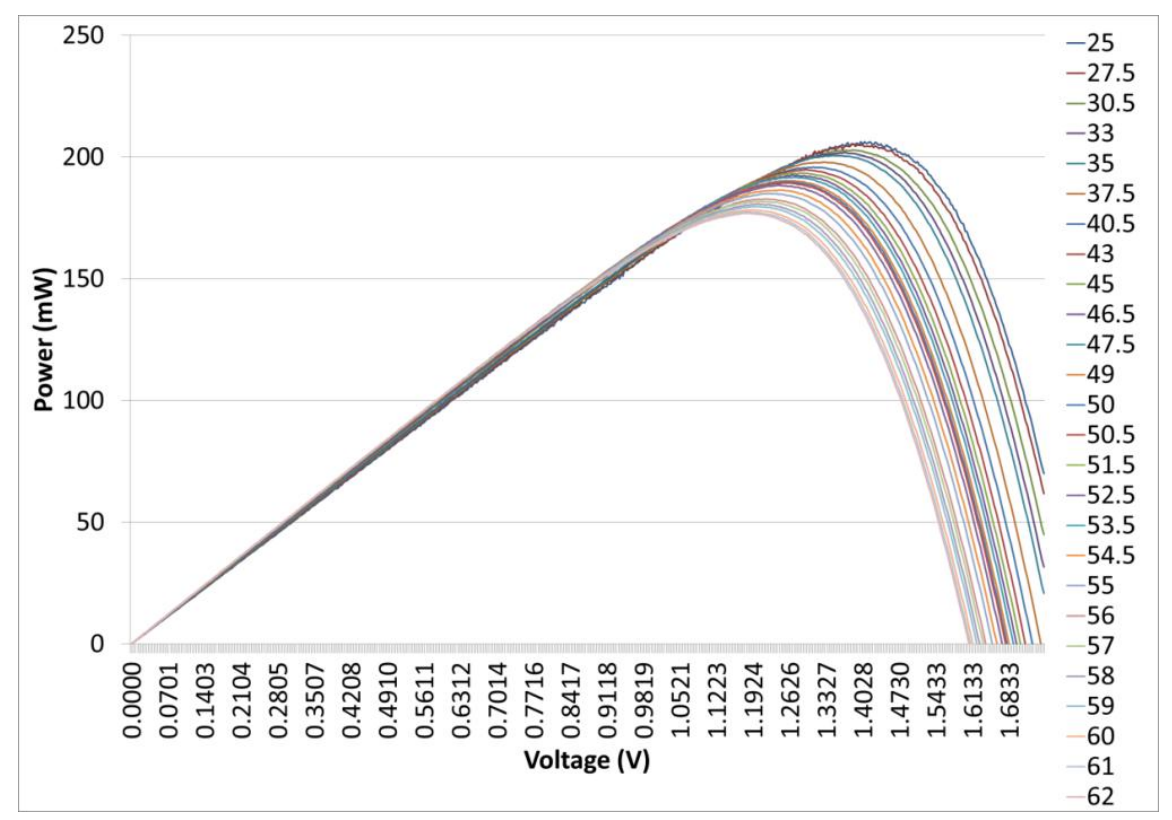

Fig.3 Temperature based P-V characteristics for the tested polycrystalline cells

Key: numbers on the right-hand side of the graph are temperature in degrees $\left({ }^{\circ} \mathrm{C}\right)$

The tested polycrystalline cells exhibited a behavior that is typical of silicone polycrystalline cells. The maximum power value for STC temperature $\left(25^{\circ} \mathrm{C}\right)$ was close to the value declared by the manufacturer amounting to $91.7 \%$ of that value. The tests temperature range from $25^{\circ} \mathrm{C}$ up to $62^{\circ} \mathrm{C}$ approximately matched the working temperatures range which normally occurs in the conventional PV panels applications (Fig.2).

On the base of the P-V characteristics obtained in the first stage of experiments, the amount of energy gained was calculated for a range of temperature points. Based on gained energy values the dependence of the PV cell energy output on its temperature was estimated to be approximately a linear relationship. The constant value of the gained energy drop amounted to $0.58 \%$ for each ${ }^{\circ} \mathrm{C}$ increase. For typical solar cells the current and voltage temperature characteristics are normally shown, but for the purposes of these experiments the energy gain temperature characteristic is more useful. The trend line illustrating this dependence is shown on figure 4. 


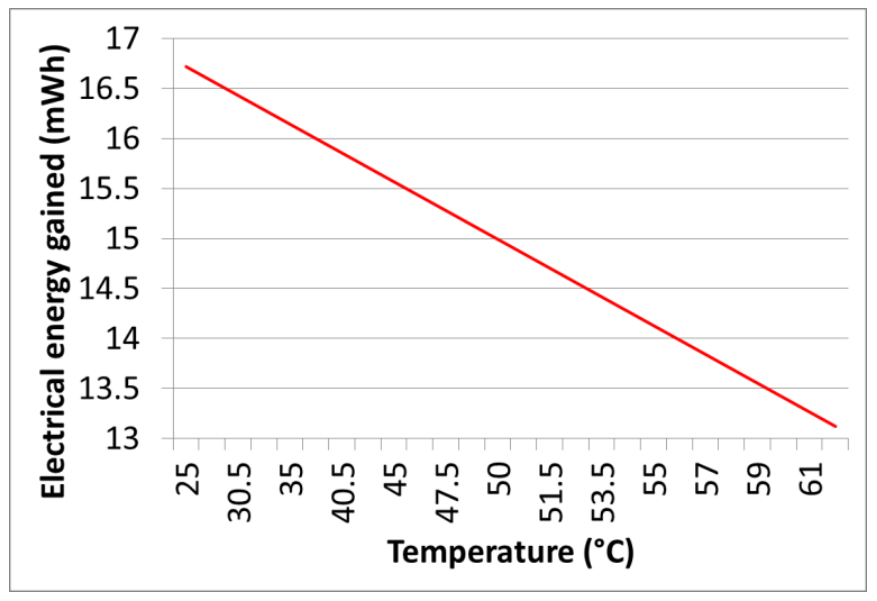

Fig. 4 PV cells temperature/electrical energy gained trend line.

\section{MULTILAYER TEG CHARACTERISTICS}

The test rig designed for the investigation of the proposed multilayer TEGs structure electrical characteristics is shown on figures 5 and 6.

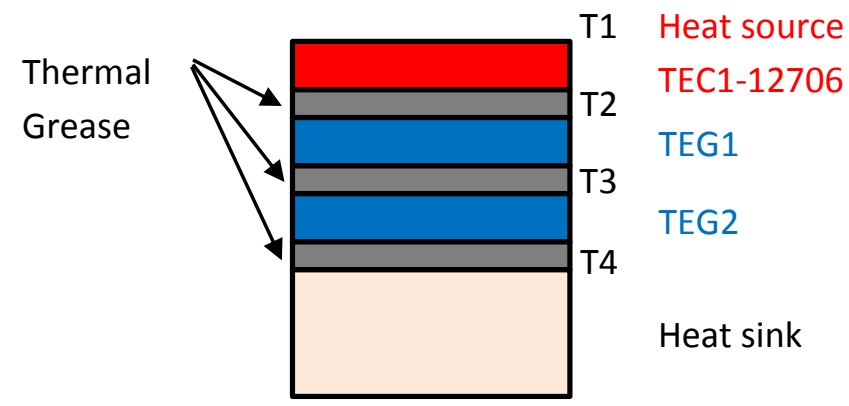

Fig.5 The tested multilayer TEGs structure with surfaces temperature indication.

Where:

T1 - heat source cold side;

T2 - connection area of the heat source (hot side) and TEG1 (hot side);

T3 - connection area of the TEG1 (cold side) and TEG2 (hot side);

T4 - connection area of the TEG2 (cold side) and heat sink; 


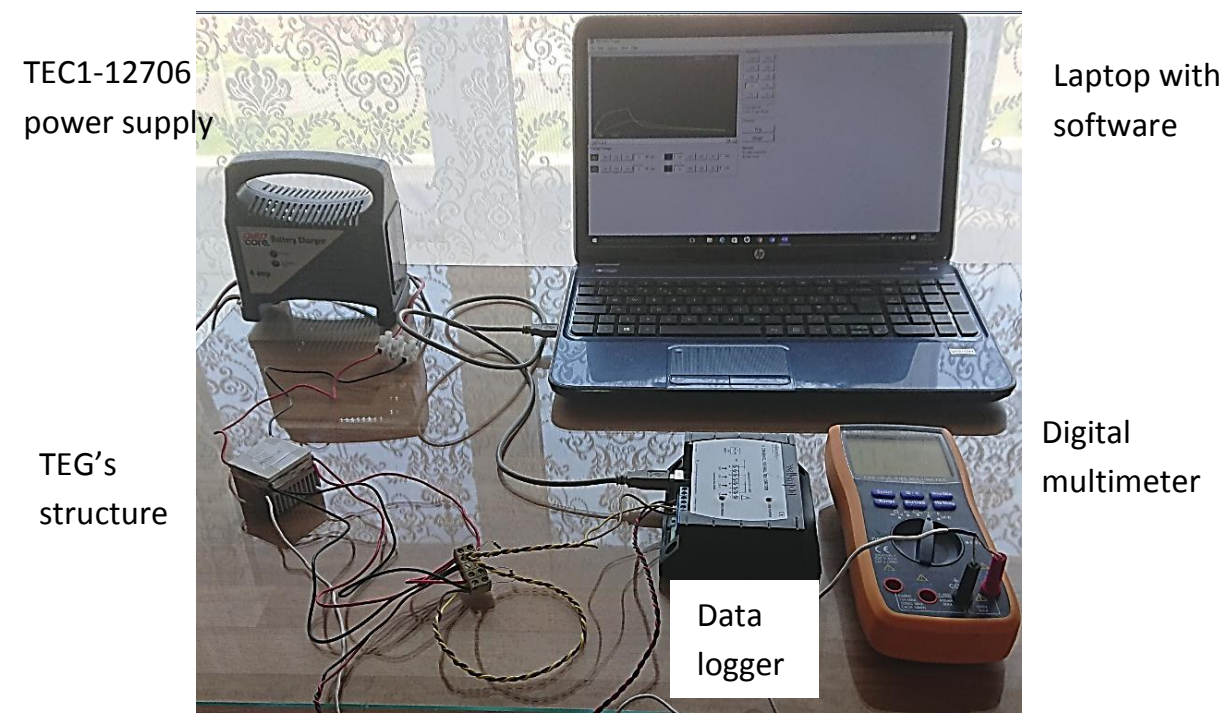

Fig.6 The TEGs multilayer energy conversion system configuration

Initially the temperature distribution in the two layer TEG's structure was examined. The temperature characteristics of TEGs are illustrated on figure 7.

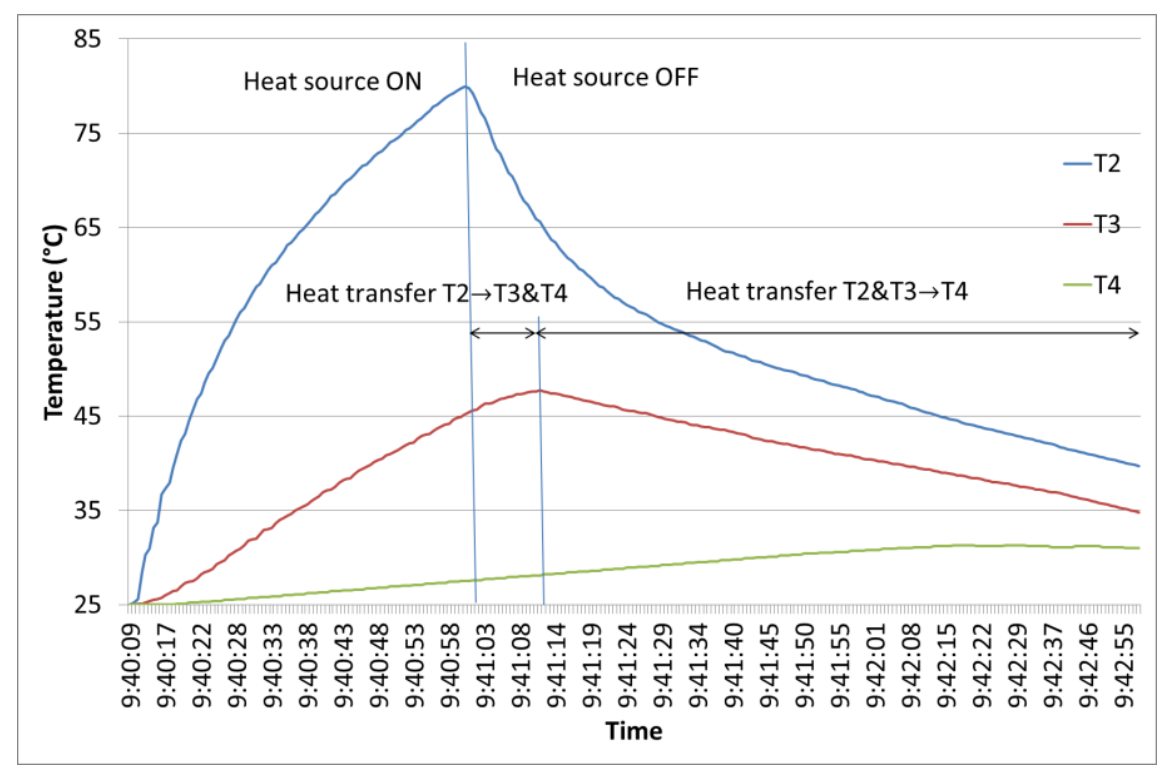

Fig.7 Temperature distribution within the 2 layers TEGs tested structure

The investigation showed that for an ambient temperature (Ta) equal to $25^{\circ} \mathrm{C}$, while temperature $\mathrm{T} 2$ increased by $54.9^{\circ} \mathrm{C}\left(79.9^{\circ} \mathrm{C}-25^{\circ} \mathrm{C}\right)$, temperature $\mathrm{T} 3$ increased by $22.7^{\circ} \mathrm{C}\left(47.7^{\circ} \mathrm{C}-25^{\circ} \mathrm{C}\right)$ which is about $41 \%$ of the $\mathrm{T} 2$ increase. Temperature $\mathrm{T} 4$ increased up to $31.3^{\circ} \mathrm{C}$ (by $6.3^{\circ} \mathrm{C}$ ) which corresponds to $11.48 \%$ and $27.8 \%$ of the $\mathrm{T} 2$ and $\mathrm{T} 3$ level of increase respectively. 
Table 1 Temperature distribution within the 2 layers TEGs tested structure

\begin{tabular}{|c|c|c|c|c|}
\hline \multirow{2}{*}{$\mathrm{T}$} & $\mathrm{T}_{\max }$ & $\begin{array}{c}\Delta \mathrm{T} \\
\mathrm{T}_{\max }-\mathrm{Ta}\end{array}$ & $\begin{array}{c}\text { Increase } \\
\text { from Ta }\end{array}$ & $\begin{array}{c}\text { Increase } \\
\mathrm{T} \text { 3\& } 4 \text { to } \\
\mathrm{T} 2\end{array}$ \\
\cline { 2 - 5 } & \multicolumn{3}{|c|}{$\left({ }^{\circ} \mathrm{C}\right)$} & \multicolumn{2}{|c|}{$\%$} \\
\hline $\mathrm{T} 2$ & 79.9 & 54.9 & 219.6 & 100 \\
\hline $\mathrm{T} 3$ & 47.7 & 22.7 & 90.8 & 41.35 \\
\hline $\mathrm{T} 4$ & 31.3 & 6.3 & 25.2 & 11.48 \\
\hline
\end{tabular}

The strong declining trend of the temperature differences $(\Delta \mathrm{T})$ between the hot and cold sides of the TEGs makes the addition of a consecutive TEG layer to the PV-TEGs structure a superfluous exercise. Thereby the three layers TEGs structure would not be economically viable because of the negligible amount of $\Delta \mathrm{T}$.

The other feature the multilayer TEG configuration exhibits is an energy accumulation phenomenon Fig.7 (heat transfers T2 $\rightarrow$ T3\&T4 and T2\&T3 $\rightarrow$ T4) occurring after the heat source is cut off. In practical applications with the TEC heat source replaced by the PV cells, the heat built up by the PV cells in operation can be used by TEGs. The energy accumulation influencing the energy conversion is a two-folded process giving both a positive and a negative effect. The advantage of energy accumulation is clearly seen in the improvement in shape of the energy conversion power characteristic (Fig.9). The stable power generation process is extended in time because partial loss of the energy converted by PV cells is compensated by energy converted by TEGs from accumulated heat. As a result of improved stability the total output of PV-TEGs structure is increased. The disadvantage is that the heat accumulated by the T4 and T3 connection (Fig.7) causes a reduction of the temperature difference between both T2-T3 ( $\Delta \mathrm{T}$ for TEG1) and T3-T4 ( $\Delta \mathrm{T}$ for TEG2) multilayer structure components as shown on figure 8 . Active cooling applied would eliminate this effect, but this solution requires additional energy.

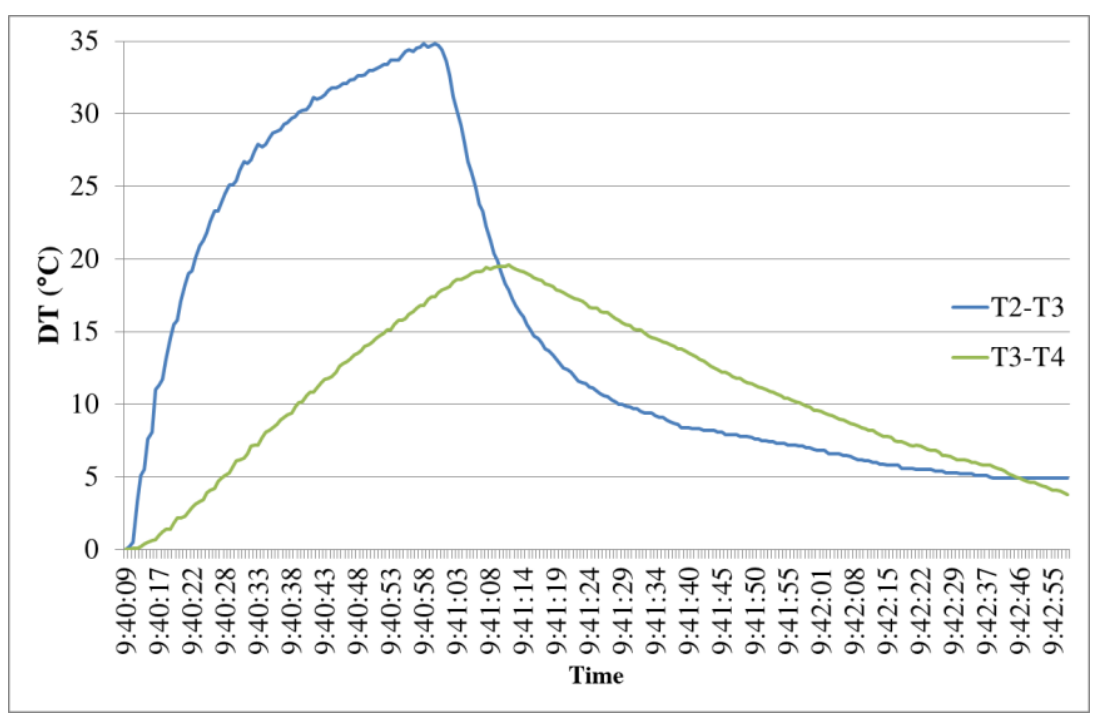

Fig.8 Comparison of the $\Delta$ T changes for TEG1 (T2-T3) and TEG2 (T3-T4)

Within the proposed structure, while TEG1 is heating up faster because of the shorter distance from the heat source, TEG2 is cooling down faster because of the shorter distance from the heat sink (Fig.8). 
The described energy accumulation effect was confirmed in the outdoor experiments. After the sun was covered by clouds and solar energy emission declined the temperature also dropped. Despite of temperature decreasing the bare PV cells performance deteriorates indicating that the reduction of insolation is more important than the drop in temperature which is expected. The TEGs-PV structure performs better than the bare PV cell utilising in addition to the limited at this time solar energy the heat accumulated by the multilayer structure components. The time of the energy conversion is extended (Fig.9).

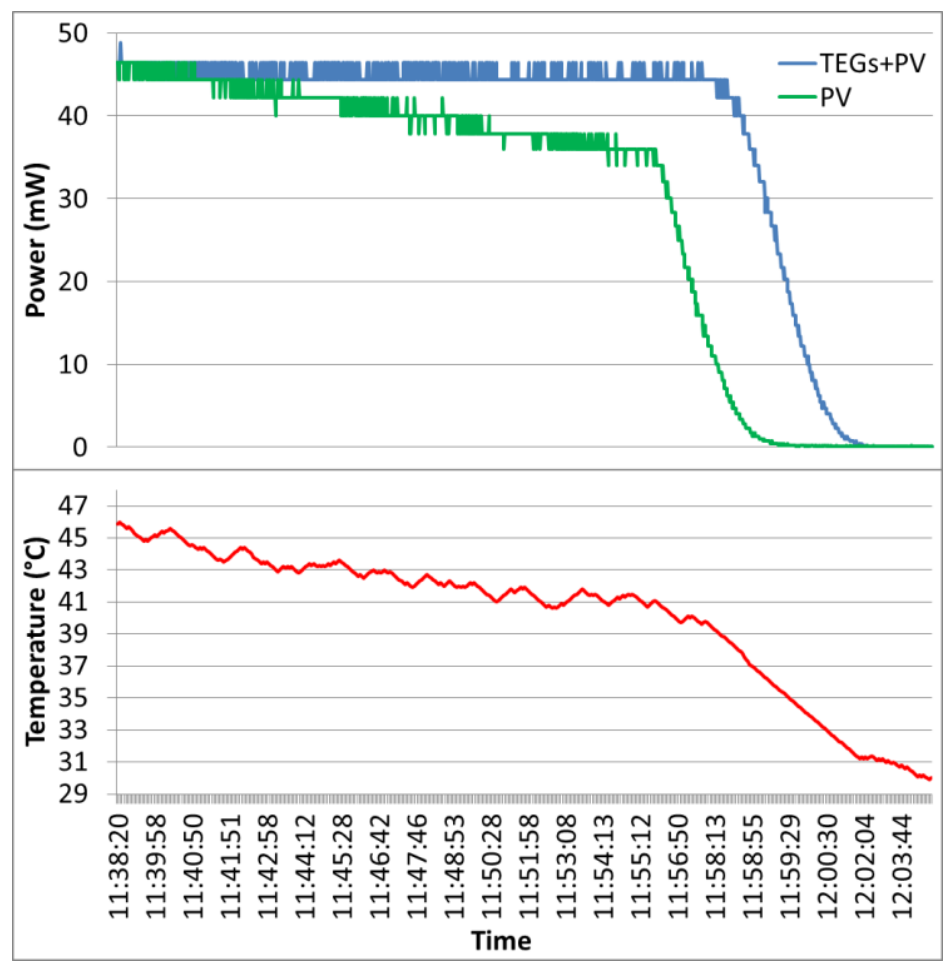

Fig.9 Energy output comparison of the bare PV and PV-TEGs multilayer structure illustrating energy accumulation effect in outdoor experiment

Over the time period presented on Fig.9 (1600s) the PV-TEGs structure produced $16.32 \mathrm{mWh}$ which is an increase of $27.6 \%$ over the bare PV output of $12.79 \mathrm{mWh}$.

Both power characteristics exhibit a similar trend as the temperature characteristic. However, the PV-TEGs characteristic is more stable than that of the bare PV and with declining amount of heat delivered by the sun irradiation the period of active energy conversion process is extended in time compared to the bare PV cell (Fig.9).

Similarly to the PV cells', the TEGs structure energy output depends on the load resistance. In order to find the optimal load resistance value a number of tests were conducted with different load sizes on the same test arrangement (Fig.5, Fig.6). As a result of those experiments the optimal load resistance for the tested configurations of the multilayer TEGs structure was established as $5 \Omega$ (Fig.10, Fig.11). 


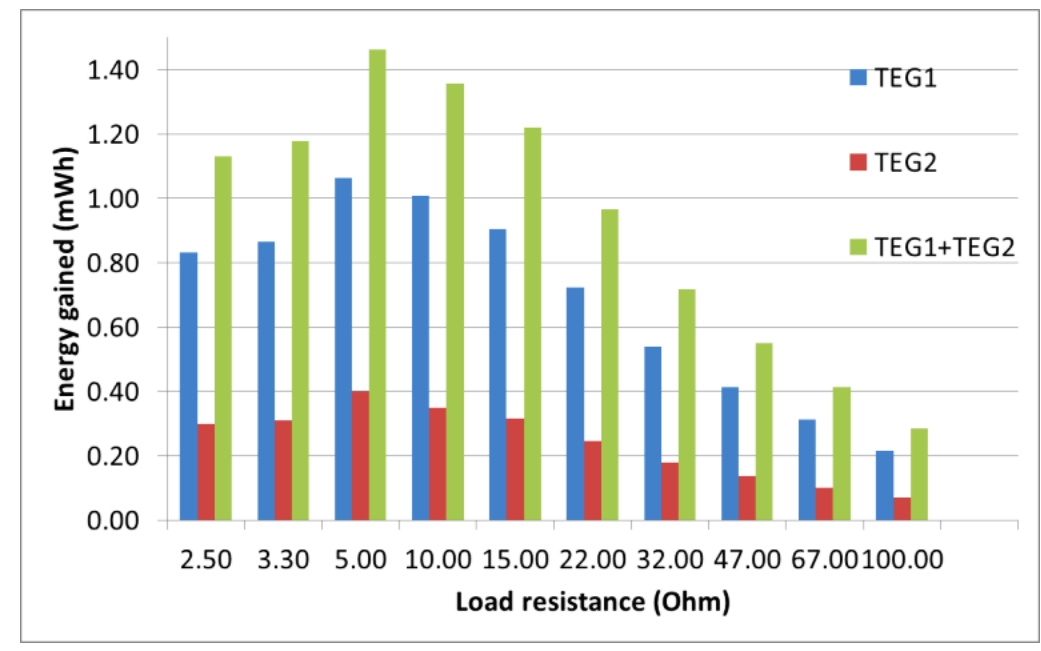

Fig.10 Comparison of energy gained by the multilayer TEGs structure for different loads resistance values.

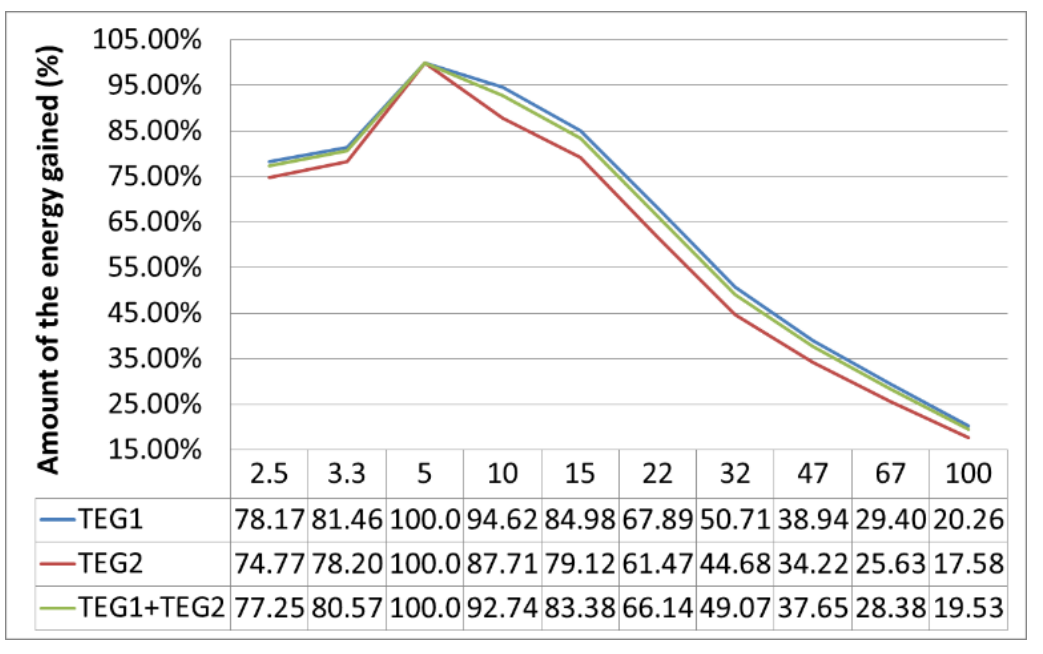

Fig.11 Comparison of the energy gained by the multilayer TEGs structure for different load resistance values, expressed as a percentage of the maximum value achieved.

Having optimal load size for the tested multilayer TEGs structure, the three options of their internal connections were tested and the influence of the TEG's connection type on the converted energy output examined. The experiments were conducted on the multilayer TEGs structure with TEGs connected in series, in parallel and independently (TEG1 + TEG2). 


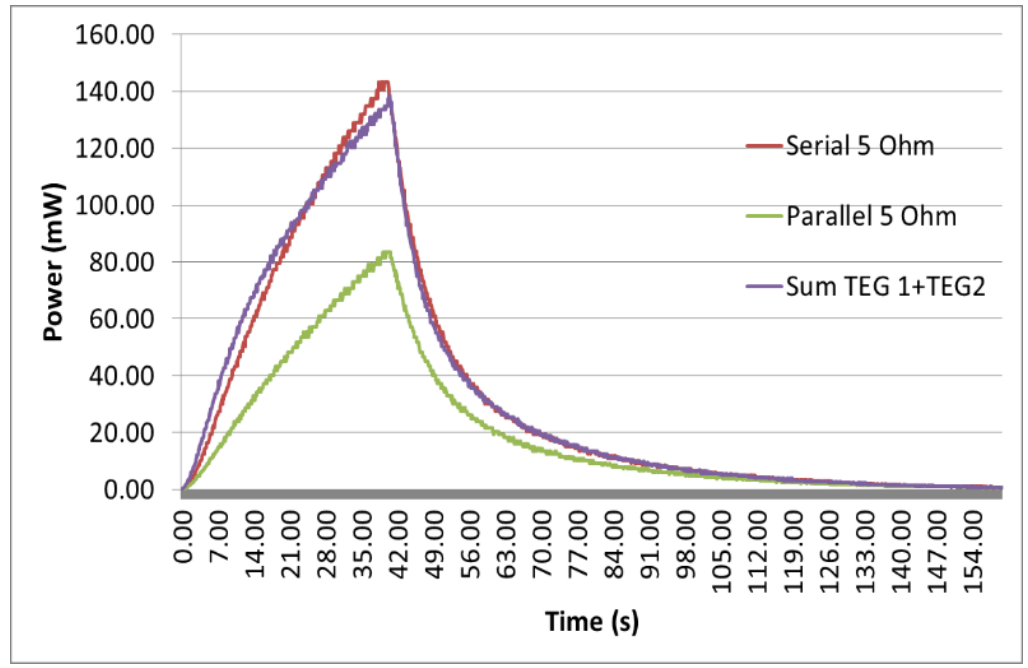

Fig.12 Power characteristics for different types of TEGs connections

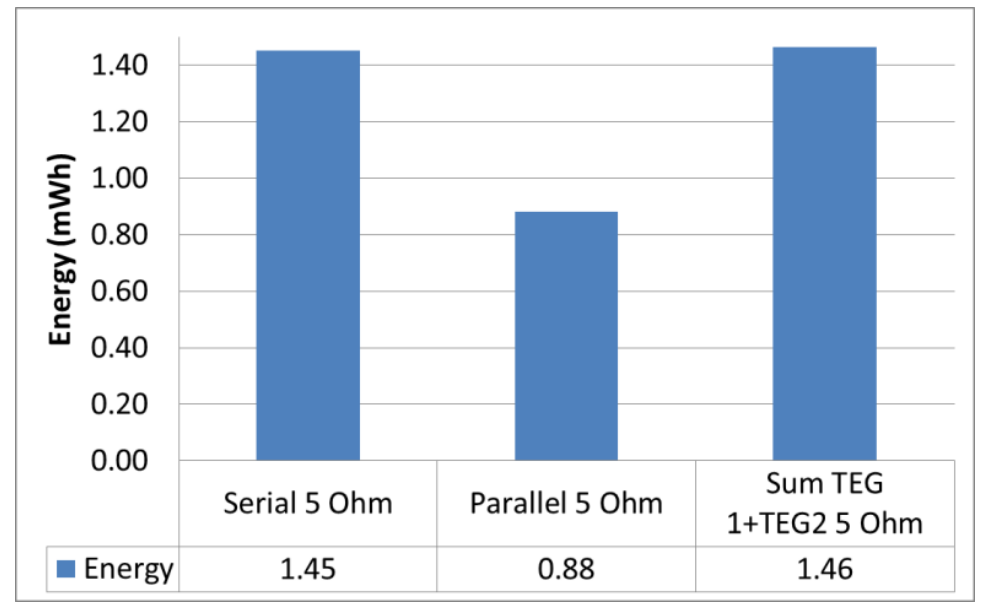

Fig.13 Gained energy for different types of TEGs connection

The investigation revealed that the highest maximum power point (MPP) for $\mathrm{T}_{\max }$ $79.9^{\circ} \mathrm{C}$ (Fig.7) was achieved by the system configuration with the TEGs serial connection (Fig.12), however a simple sum of the TEGs energy outputs using two separated electrical energy converters utilizing constant input resistance could be slightly more effective at the initial temperature rise stage (Fig. 12). The parallel TEGs connections proved to be considerably less efficient.

\section{PV-TEGS HYBRID SYSTEM}

For investigation of the hybrid PV-TEGs system an independent polycrystalline silicone PV cells and TEGs connected in series configuration was selected. The $\mathrm{V}_{\text {oc }}$ test of the system conducted in outdoor conditions on 25 Apr 2020 showed that the voltage produced by the sum of the PV and TEGs was up to $30.54 \%$ higher than the voltage produced by the bare PV cells structure. Therefore, it was confirmed experimentally that the hybrid PV-TEGs energy system performance is significantly higher as compared to bare PV cells. The examination of the PV-TEGs structure temperature characteristic (Fig.15) 
against its voltage output characteristic (Fig.14) showed that the energy conversion process by TEGs continued up to the point in time when temperature fell down to $25^{\circ} \mathrm{C}$ at 19:07:38. This outcome is associated with the power characteristics of the thermo-electrical generators applied.

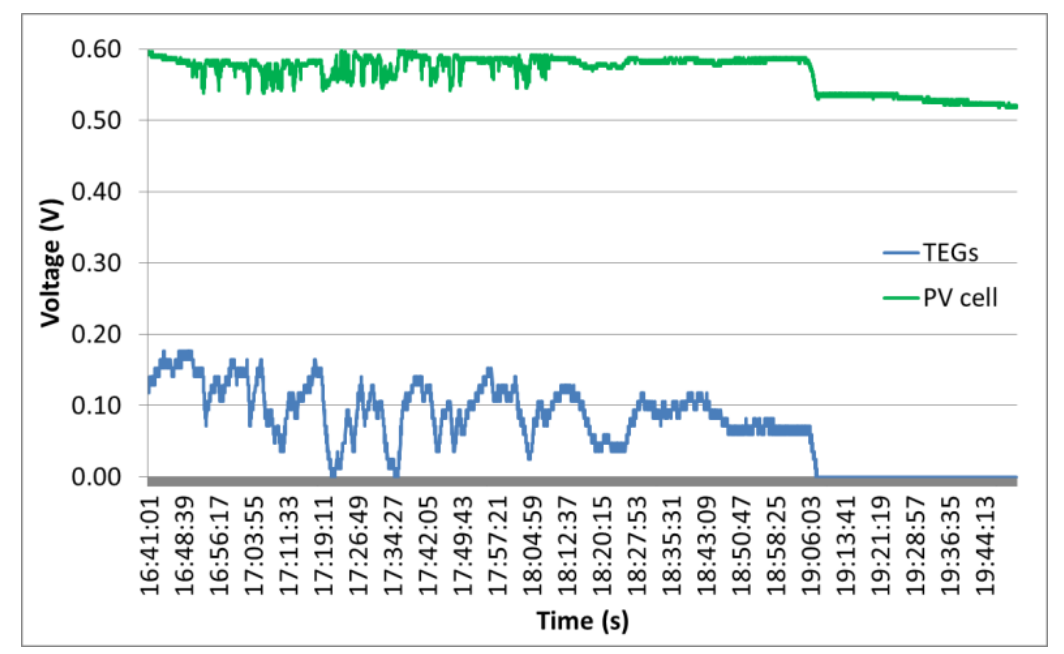

Fig.14 Voc generated by PV and TEGs structure for the selected PV-TEGs hybrid system.

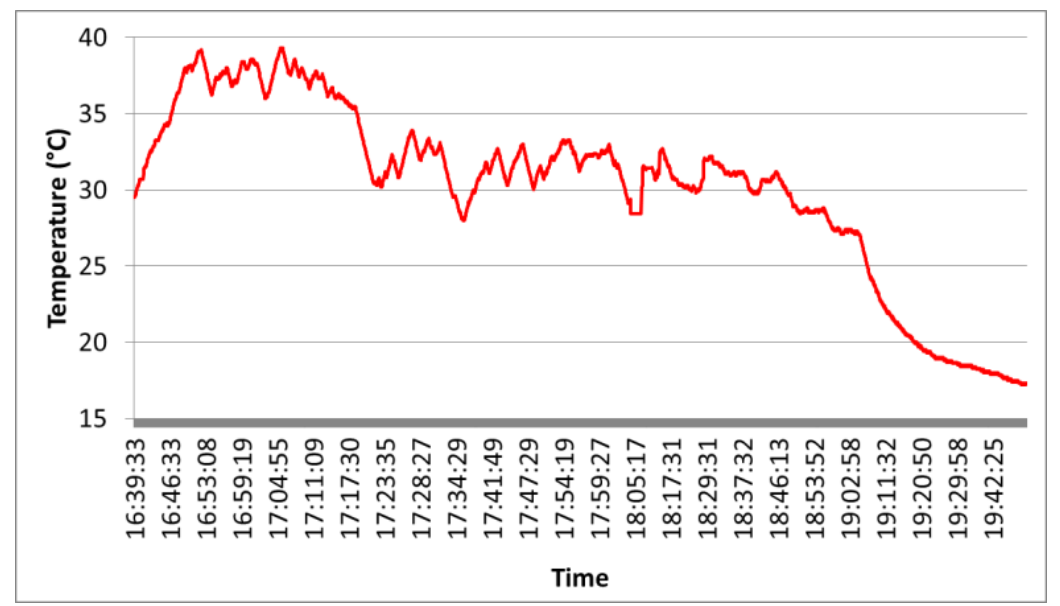

Fig.15 Temperature characteristics for the selected PV-TEGs hybrid system

The similar test illustrated example of the general elements behavior was conducted in the laboratory conditions with $\mathrm{T}_{\mathrm{a}}=25^{\circ} \mathrm{C}$ and $\mathrm{R}_{\mathrm{L}}=22 \Omega$ both for the PV and TEGs structure, with the constant source of solar irradiation of $1000 \mathrm{~W} / \mathrm{m}^{2}$ from an artificial solar simulator Sol3A series. The resulting temperature and voltage characteristics of this test are shown on figures 16 . 


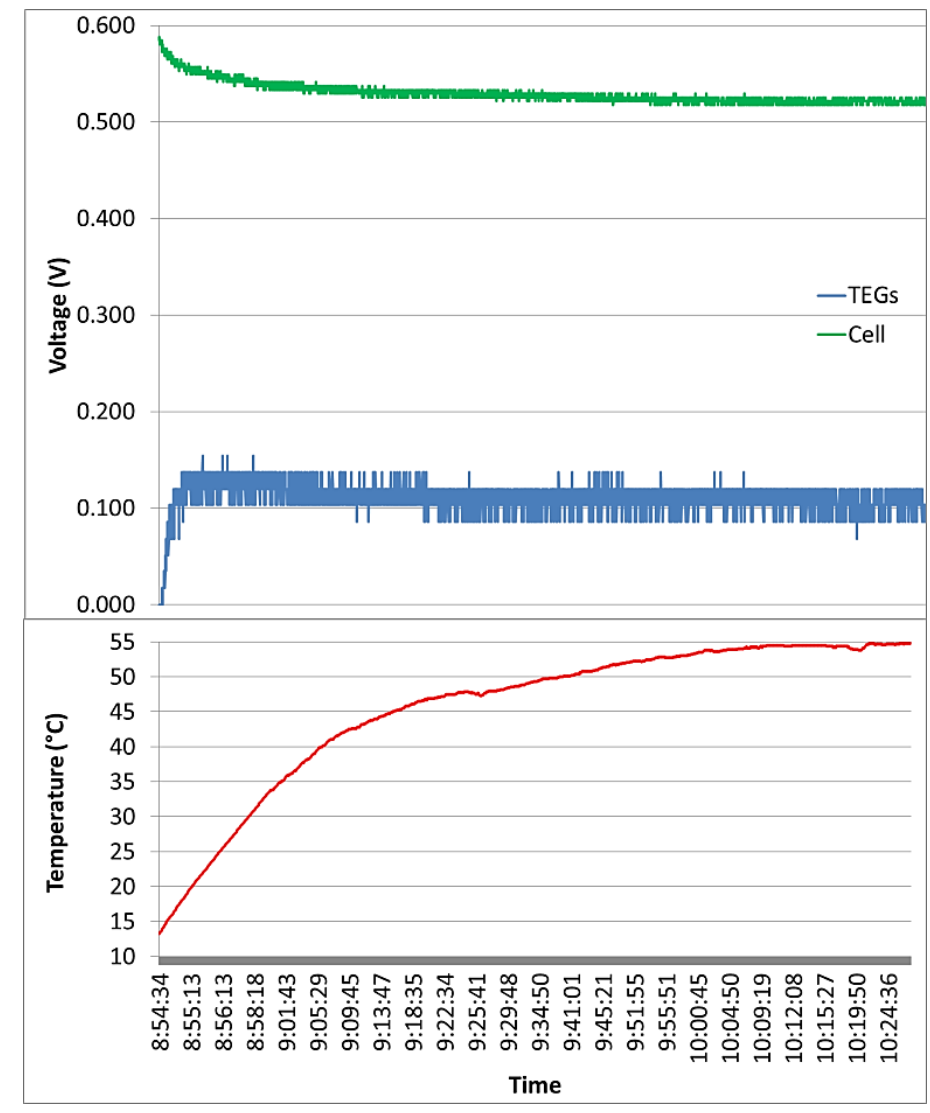

Fig.16 Voltage and temperature characteristics for the hybrid PV-TEGs structure in the indoor test

The laboratory test like the outdoor experiment confirmed constant generation of electrical energy by the TEGs structure. The TEGs voltage generation level reached approximately $28.56 \%$ of the voltage generated by bare PV cells structure. The shape of both voltage characteristics exhibited a declining trend with temperature rising. Compared to the non-cooled PV structure (Fig.2), the maximum PV cells temperature is lower by $10.3^{\circ} \mathrm{C}$, which significantly influences the resulting PV cells efficiency.

The comparison of the voltage characteristics obtained in the outdoor and indoor experiments indicated that under real sun conditions the efficiency of the TEGs structure is slightly higher ( $30.54 \%$ vs $28.56 \%$ ), which is related to better outdoor cooling conditions such as wind and humidity. The other factor decreasing energy conversion efficiency is the laboratory constant light. In comparison to the real solar radiation, a stable light source causes higher PV-TEGs structure heating.

\section{CONCLUSIONS}

Researchers have been long looking for the most effective way to increase the silicone PV cells yield by applying hybrid PV-TEG structures. The solutions ranged from directly applying TEGs to a silicone PV structure [14] to using an indirect connection through the heat exchanger [15]. Both methods are based on utilizing low (direct) and high (indirect) $\Delta \mathrm{T}$ and use a simple one layer TEG structure. The solution proposed in this paper involves the application of a multilayer TEGs structure applied directly to silicone PV cells. The performed tests confirmed that the efficiency of the hybrid PV-TEGs solar energy 
conversion system is significantly higher than the efficiency of the bare PV cells with the 2 layer TEGs configuration being the optimal solution. The experiments conducted on the small samples showed further improvement of the solar energy conversion efficiency in the two layer TEGs structure with the TEGs connected in series and the optimal load resistance of $5 \Omega$ (Fig.11).

Analysis of the results of the indoor experiments (Fig.16) assuming a load of the TEGs of $5 \Omega$ (1.505 factor was used to recalculate the load - Fig.11) indicated that the PV-TEGs system over the test period of 5548s gained $20.29 \mathrm{mWh}$ which compared to the energy output of the bare PV system of $19.68 \mathrm{mWh}$ represents an improvement of about $3.1 \%$. This increase is equivalent of the higher power output by about $5.58 \mathrm{~W} / \mathrm{m}^{2}$ which provides an improvement in energy conversion efficiency from $18 \%$ to $18.558 \%$. The PV cells temperature reduction reached about $10^{\circ} \mathrm{C}$ confirming the result obtained by Arifin et.al.[6]. The outdoor experiments showed for selected period of time at insulation decline caused by clouds the energy output increased by $27.6 \%$ compared to plain PV cells (Fig.9).

Additionally the shape of the power output characteristic (Fig.9) could be improved by accumulated heat energy utilization which would enhance grid stability in large solar systems [16]. The efficiency gain could be even higher under certain conditions which would require use of the dedicated TEGs structures specifically designed for operation in low temperatures settings. The further research area that can be recommended lies in optimizing the structure of the energy conversion systems elements and cover issues related to both increasing of energy conversion process efficiency and effective use of the heat accumulated by the system. 


\section{REFERENCES}

[1] REN21 Renewables Global Status Report, URL: https://www.ren21.net/reports/globalstatus-report/ (2020)

[2] M. Woodhouse B. Smith A. Ramdas R. Margolis, Crystalline Silicon Photovoltaic Module Manufacturing Costs and Sustainable Pricing: 1H 2018 Benchmark and Cost Reduction Road Map, Technical Report NREL/TP-6A20-72134, Revised February 2020, URL: https://www.nrel.gov/docs/ fy19osti/72134.pdf, (2020)

[3] B. Lorenzi D. Narducci M. Accuarri, Experimental Determination of Power Losses and Heat Generation in Solar Cells for Photovoltaic-Thermal Applications, Journal of Materials Engineering and Performance · August 2018, DOI: 10.1007/s11665-018-3604-3 (2018)

[4] D. Pushpendu K. Dwivedia S. Archana E. Solomin J. Kirpichnikova, Advanced cooling techniques of P.V. modules: A state of art. Case Studies in Thermal Engineering Volume 21, (October 2020)

[5] S. Kalaiselvan V. Karthikeyan G. Rajesh A. Sethu Kumaran B. Ramkiran P. Neelamegam, Solar PV Active and Passive Cooling Technologies - A Review, International Conference on Computation of Power, Energy, Information and Communication (ICCPEIC), 28-29 March 2018, DOI: 10.1109/ICCPEIC.2018.8525185 (2018)

[6] Z. Arifin D. D. D. P. Tjahjana S. Hadi R. A. Rachmanto G. Setyohandoko B. Sutanto, Numerical and Experimental Investigation of Air Cooling for Photovoltaic Panels Using Aluminum Heat Sinks. Hindawi, International Journal of Photoenergy Volume 2020, Article ID 1574274, 9 pages https://doi.org/10.1155/2020/1574274 (2020)

[7] J. Kim S. Bae Y. Yu Y. Nam, Experimental and Numerical Study on the Cooling Performance of Fins and Metal Mesh Attached on a Photovoltaic Module, Energies 2020, 13, 85; doi:10.3390/en13010085, (2020)

[8] S. A. Rakin S. Suherman S. Hasan A. H. Ramble A. Gunawan, Passive Cooling System for Increasing Efficiency of Solar Panel Output, The 2019 Conference on Fundamental and Applied Science for Advanced Technology, Journal of Physics: Conference Series, 1373 012017, doi:10.1088/1742-6596/1373/1/012017, (2019)

[9] M. I. Yusoff M. Irwanto L. Wai Zhe G. Nair, Cooling on photovoltaic panel using forced air convection induced by DC fan, International Journal of Electrical and Computer Engineering (IJECE) Vol. 6, No. 2, April 2016, pp. 526-534 ISSN: 2088-8708, DOI: 10.11591/ijece.v6i1.9118 (2016)

[10] U. Lachish, Thermoelectric Effect Peltier Seebeck and Thomson, URL: https://www.researchgate.net/publication/340173454_Thermoelectric_Effect_Peltier_ Seebeck_and_Thomson, DOI: 10.13140/RG.2.2.25436.13444, (2020)

[11] D. Narducci P. Bermel B. Lorenzi N. Wang K. Yazawa, Hybrid PhotovoltaicThermoelectric Generators, Theory of Operation, Springer Series in Materials Science DOI: 10.1007/978-3-319-76427-6_5, In book: Hybrid and Fully Thermoelectric Solar Harvesting, (2018)

[12] E. Kanimba Z. Tian, Modeling of a Thermoelectric Generator Device, DOI: $10.5772 / 62753,(2016)$ 
[13] B. Lorenzi G. Chen, Theoretical efficiency of Hybrid Solar ThermoelectricPhotovoltaic Generators, Journal of Applied Physics · July 2018, DOI: 10.1063/1.5022569, (2018)

[14] N. M. Shatar M. A. A. Rahman N. M. Muhtazaruddin S. A. Z. S. Salim B. Singh F. Muhammad-Sukki N. A. Bani A. S. M. Saudi J. A. Ardila-Rey, Performance Evaluation of Unconcentrated Photovoltaic-Thermoelectric Generator Hybrid System under Tropical Climate, Sustainability 2019, No.11, 6192; doi:10.3390/su11226192, (2019)

[15] A. A. Bayod-Rújula A. Martínez-Gracia A. Del Amo M. Cañada S. Usón J. Uche J. A. Tejero, Integration of Thermoelectric generators (TEG) in Solar PVT panels, International Conference on Renewable Energies and Power Quality (ICREPQ'19) Tenerife (Spain), 10th to 12th April, 2019, ISSN 2172-038 X, Volume No.17, (2019)

[16] H. Al Smadi, Overview of Grid-Connected PV Systems Challenges with Regards to Grid Stability, Solar Energy Engineering, June 2018, URL: https://www.researchgate.net/publication/334303839_Overview_of_Grid-Connected_PV_ Systems_Challenges_with_Regards_to_Grid_Stability, (2018) 